\title{
Primary tuberculosis of epiglottis-A case report
}

\author{
Sanjeev Tandon, K.B. Gupta, Rajnish Kalra*, Rajeev Sen*
}

\begin{abstract}
Abstrak
Tuberkulosis laring umumnya sekunder terhadap lesi tuberkulosis di bagian tubuh lain, dan jarang sekali yang primer. Dilaporkan satu kasus tuberkulosis epiglottis primer.
\end{abstract}

\begin{abstract}
Laryngeal tuberculosis is commonly secondary to a tuberculous lesion in the body or rarely primery. We are reporting a rare case of primary tuberculosis of epiglottis.
\end{abstract}

Keywords: tuberculosis, larynx, epiglottis

Tuberculosis of the larynx has become relatively uncommon, since the advent of effective antitubercular chemotherapy. Laryngeal tuberculosis is commonly secondary to a tuberculous lesion elsewhere in the body or rarely, a primary affection from direct invasion by inhaled tubercle bacilli. We are reporting a case of primary tuberculosis of epiglottis.

\section{CASE REPORT}

A 55 year old male presented with a two months history of hoarseness of voice and dry cough. There was no hemoptysis, fever, night sweats, malaise or weight loss. The patient had been a chronic smoker until recently. There was no history of previous tuberculosis or contact with a case of pulmonary tuberculosis. The patient was anaemic without any lymphadenopathy. Respiratory system examination was normal. An indirect laryngoscopy revealed, a white thickened area in the anterior third of the epiglottic region. The left ventricle was pale and granular. Both vocal cords were mobile.

In the laboratory investigation, haemoglobin was 9.6 $\mathrm{g} \%$, total leucocyte count $7800 / \mathrm{mm}^{3}$, erythrocytic sedimentation rate was $20 \mathrm{~mm} / 1^{\text {st }}$ hour (Westergren). All other biochemical parameters were normal. Chest

Department of Chest and TB and Pathology*

Pt. B.D. Sharma PGIMS, Rohta 124001

Haryana, India
X-ray did not reveal any parenchymal or pleural pathology. Ultrasound abdomen was normal. Bronchoscopic examination revealed no abnormality. BAL was negative for acid fast bacilli. Mantoux test was positive. Direct laryngoscopy findings confirmed the presence of a keratotic lesion in the anterior third of the epiglottic region. Biopsy of the epiglottis revealed scattered epitheloid cell granulomas with Langhans giant cells surrounded by lymphocytes and fibroblasts, with few areas of caseation necrosis and positive staining for acid fast bacilli suggestive of tuberculosis (Figure1). Treatment was instituted with rifampicin (450 mg), isoniazid (300 mg), ethambutol $(800 \mathrm{mg})$ and pyrazinamide $(1500 \mathrm{mg})$. There was prompt improvement in symptoms, within a week of commencing treatment and the patient was asymptomatic within two months.

\section{DISCUSSION}

Only a few years ago, tuberculosis was one of the commonest laryngeal diseases and the prognosis was extremely poor. Today, tuberculosis is one of the uncommon laryngeal diseases, and its prognosis is excellent. It may be primary or secondary. Most authorities believe that the laryngeal infection is usually secondary to pulmonary tuberculosis, the larynx being inoculated with bacilli from the infected sputum or from the lungs via lymphatic and hematogenous routes. In a series of 37 cases of laryngeal tuberculosis only 3 cases involved the epiglottis, and it was secondary to pulmonary tuberculosis. ${ }^{1}$ 


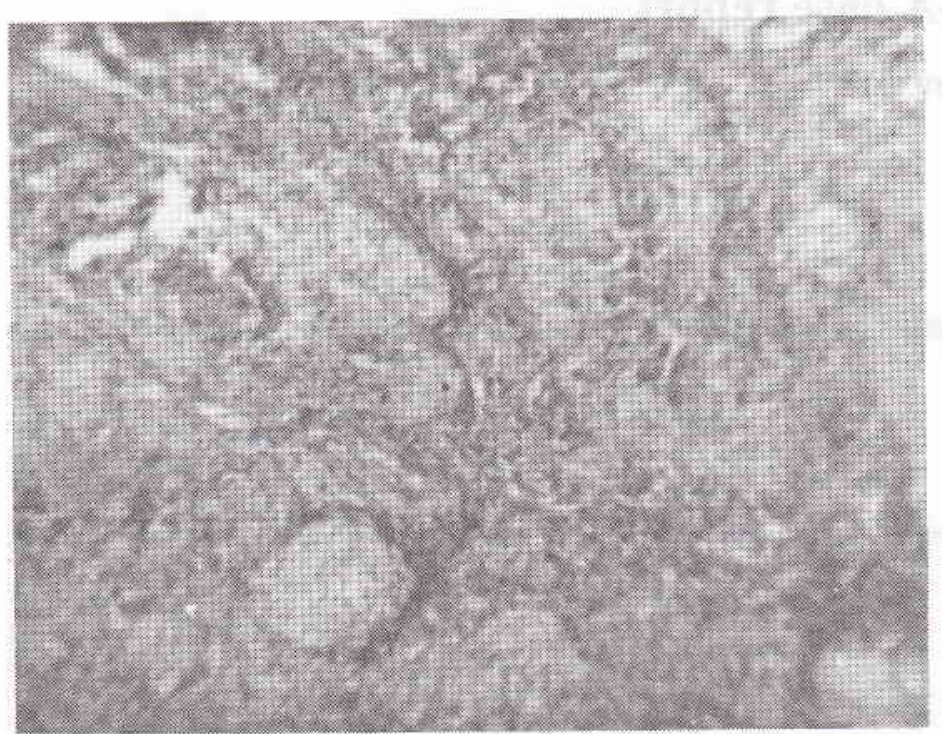

Figure 1. Microphotograph showing granulamatous Inflammation involving acini and ducts of minor salivary glands present in epiglottis
Primary laryngeal tuberculosis is rare, the accepted route of infection is direct invasion by inhaled tubercle bacilli. In the present case the diagnosis of primary laryngeal (epiglottis) tuberculosis was considered likely as there was no evidence of the disease in any other organ or system. The differential diagnosis of laryngeal tuberculosis includes, chronic non specific laryngitis, syphilis, and carcinoma. ${ }^{2-4}$ The diagnosis of laryngeal tuberculosis is established by identification of a caseating granuloma in a biopsy specimen. A chest $\mathrm{X}$-ray must be done in all patients with chronic laryngitis however, a negative skiagram chest does not exclude the possibility of laryngeal tuberculosis, as is evident in the present case.
A high index of suspicion and awareness will prompt the clinician to establish tissue diagnosis by direct laryngoscopy and biopsy. Early diagnosis is important because once recognised, tuberculous infection of the larynx may be readily eradicated by medical treatment.

\section{REFERENCES}

1. Bailey MC, Taylor WPC. Tuberculous laryngitis: A series of 37 patients. Laryngoscope 1981; 91:93-100.

2. Bull TR. Tuberculosis of the larynx. Br Med J 1996; 2:991-2.

3. Chodosh PL, Willis W. Tuberculosis of the upper respiratory tract. Laryngoscope 1970; 80 (5):679-96.

4. Hunter AM, Millar JW, Wightman AJA, Horne NW. The changing pattern of laryngeal tuberculosis. J Laryngol Otol 1981; 95:393-8. 